\title{
Prospects of Wind Energy in Bagwai for Irrigation Scheme
}

\author{
S. M. Lawan \\ Department of Electrical Engineering, Kano University of Science and Technology, Wudil Nigeria
}

\begin{abstract}
A 10 years data (2002-2012) was used to analyse the possibility of using weibull probability distribution function method to generate power for irrigational pumping machine, the mean and extractable power densities were found to be $22.75 \mathrm{w} / \mathrm{m}^{2}$ and $13.49 \mathrm{Kwh} / \mathrm{m}^{2}$ at $25 \mathrm{~m}$ height respectively, this indicate strongly that there is potential wind energy available for use in pumping water at the study site.
\end{abstract}

Key words: Wind speed, Weibull distribution, Power and Energy Densities

\section{Introduction}

Wind is the approximate horizontal movement of air, which arises due to differences of atmospheric pressure, which in turn is caused, by the temperature variations or gradient in the atmosphere above the earth. The Earth's equatorial regions received more solar radiation than the Polar Regions and this cause large-scale convection current in the atmosphere. Since the sun provides the heat to warm the air that leads to wind, we may say that, the wind energy is an indirect form of solar energy. Other direct forms of solar energy are tidal, organic fuels etc. It has been estimated that, between 1-2\% of all solar energy reaching the earth is converted in to wind energy [1]

Wind was probably first used for energy in the field of transportation, and it is believed that the ancient Egyptians used it to power their trading vessels as far back as the year 5000 B.C. By the year 2000 B.C. the Persians had developed the first vertical axis wind mills that were used to pump water and power simple machines. (e.g. to grind grains). In the $12^{\text {th }}$ century A.D. Europeans were using horizontal axis windmills to provide part of their mechanical energy needs. By 1890 Denmark had developed the first electricity producing wind turbines. In the late $19^{\text {th }}$ century also settlers took the technology to the new world for pumping water for farms and ranches and later, to generate electricity [2] The colonial masters brought windmills to Nigeria. Though not in use, most of these equipments can still be seen in almost every district headquarters and major villages of the old Kano State.

The people of the northern part of this country are predominantly farmers. They practice both the irrigation and rainwater farming. The irrigation system covers from the earliest man-powered shaduf through the use of small petrol engines and larger diesel engine to the few gravitationally feed dams (e.g. Dingare dam, Jigawa State, Tiga and Thomas dams, Kano State). With all these development in irrigation, one seldom sees a windmill turbine system in use. Most part of the irrigation activity involves the use of the fueled machines, (Bagwai, Jekarade and Dambo fall in this category. As observed since last decades, the hike in fuel price is becoming a continues phenomenon, development of wind energy generators for irrigation is very important. Apart from this, the occasional breakdown of these machines is even more catastrophic than the fuel price. In 2004, the breakdown of a diesel engine in Bagwai result in complete dry up of about 72 acres of cultivated land amounting to the loss of several thousands of Naira

This paper will help in the development of distributed wind generators or a wind farm for irrigation to support the existing diesel pumps. It is a known fact that wind generators working parallel with diesel machines can reduce the fuel consumption by about $40 \%$ [3] It is free apart from the capital cost. No pollution hazard to the surrounding. It helps the government to mount a long lasting program that boost the economy of the common man and the country at large.

\section{Wind Speed}

\section{Theoretical Background}

To assess the variation of wind speed of an area over an extended period of time, it is good to estimate the frequency of occurrence of each wind speed. The often-used distribution functions to estimate this frequency is the Weibull distribution function [4]

The weibull distribution function $f_{w}(v)$ is given by:

$$
f_{w}(v)=\left(\frac{k}{c}\right)\left(\frac{v}{c}\right)^{k-1} \exp \left[-\left(\frac{v}{c}\right)^{k}\right]_{k>0, c>0}
$$

Where $v$ the velocity of the wind is, $k$ is the shape parameter (dimensionless), $c$ is the scale parameter $(\mathrm{m} / \mathrm{s})$ 
The weibull distribution function has a cumulative distribution function $F_{w}(v)$ given by:

$F_{w}(v)=1-\exp \left[-\left(\frac{v}{c}\right)^{k}\right]$

If $\mathrm{k}=2$, then the weibull function will become Rayleigh $f_{r}(v)$ given by:

$$
f_{r}(v)=\frac{\pi}{2} \frac{v}{v_{m}^{2}} \exp \left[-\frac{\pi}{4}\left(\frac{v}{v_{m}}\right)^{2}\right]
$$

And the corresponding cumulative function

$$
F_{r}(v)=1-\exp \left[-\frac{\pi}{4}\left(\frac{v}{v_{m}}\right)^{2}\right]
$$

$v_{m}=$ mean wind speed

Accordingly, the number of hours in a year with $v>v_{x}$ is given by

$$
T(v)=8760 \exp \left[-\left(\frac{v}{c}\right)^{k}\right]
$$

The values of $\mathrm{k}$ and $\mathrm{c}$ can be estimated using any of the following methods:

1. Weibull probability paper.

2. Rank regression.

3. Energy pattern factor analysis

4.

\section{Estimation Of K And C Using Rank Regression On Y}

Performing rank regression on $\mathrm{Y}$ requires that a straight line mathematically be fitted to a set of data points such that the sum of the squares of the vertical deviations from the points to the line is minimised. [5] Taking the natural logarithm of both sides of equation 2 yields

$$
\begin{aligned}
& \ln \left[1-F_{w}(v)\right]=-\left(\frac{v}{c}\right)^{k} \\
& \ln \left\{-\ln \left[1-F_{w}(v)\right]\right\}=k \ln \left(\frac{v}{c}\right) \\
& \ln \left\{-\ln \left[1-F_{w}(v)\right]\right\}=-k \ln (c)+k \ln (v) \\
& \text { Let } \\
& y=\ln \left\{-\ln \left[1-F_{w}(v)\right]\right\} \\
& a=-k \ln (c) \\
& b=k \\
& x=\ln (v)
\end{aligned}
$$

Equation 6 becomes a linear equation of the form: $y=a x+b$

$$
\begin{aligned}
a= & \frac{\sum_{i=1}^{N} y_{i}}{N}-b \frac{\sum_{i=1}^{N} x_{i}}{N} \\
b= & \frac{\sum_{i=1}^{N} x_{i} y_{i}-\frac{\sum_{i=1}^{N} x_{i} \sum_{i=1}^{N} y_{i}}{N}}{\sum_{i=1}^{N} x_{i}{ }^{2}-\left[\frac{\left(\sum_{i=1}^{N} x_{i}\right)^{2}}{N}\right]}
\end{aligned}
$$

The Fw(v)are estimated from Median Ranks (MR)

$$
M R \%=\frac{i-0.3}{N+0.4} * 100
$$

Where $\mathrm{i}$ is the order number and $\mathrm{N}$ the total sample size 
The wind speeds depend on location and the ground roughness. It is not possible to mount the measuring device in every location. When the wind speed distribution is needed for a site that has no record of wind data, the speed for the site is estimated from the data of a nearby station, [6] thus:

Ws $($ Area you want $)=[$ Ws (Area you Know) $x$ Coefficient (Area you want) $] /$ Coefficient (Area you want)

\section{Wind Shear}

Wind speeds increase with vertical height in the earth's boundary layer. This is because the wind near the earth surface is retarded due to the roughness caused by trees, buildings and crops. This characteristic of the wind is termed wind shear or vertical shear. The function often used to model vertical shear is given in equation 11 below [7-8]

$$
\frac{V_{(h)}}{V_{(h 1)}}=\left(\frac{h}{h_{1}}\right)^{\alpha}
$$

Where $\mathrm{V}_{(\mathrm{h})}$ is the wind speed at height (h), $\mathrm{V}\left(\mathrm{h}_{1}\right)$ is the wind speed at reference height $\mathrm{h}=\mathrm{h}_{1}, \alpha$ is $\mathrm{c}$ the power coefficient and has value $\alpha=1 / 7$

\section{Wind Power (Available And Extractable)}

The wind is a moving mass of air, therefore, it poses a kinetic energy which can be harvested by a rotor or a wheel and transferred to a rotating shaft. Energy in the shaft is then used to derive mechanical or electrical loads. This kinetic energy $(\mathrm{K})$ is given by:

$$
K=1 / 2 M v_{f}^{2}
$$

Where $\mathrm{M}=$ mass of the air passing/striking the wheel, $\mathrm{v}_{\mathrm{f}}$ is the velocity (free stream velocity

If $\mathrm{A}$ is the area through which volume $\mathrm{V}$ of air passing in a time $\mathrm{t}$, and $\rho$ the density of the air, then

$\mathrm{M}=\rho \mathrm{V}$

Or $\mathrm{M}=\rho \mathrm{A}$ vf $\mathrm{t}$

Substituting $\mathrm{m}$ in equation 12 yields

$$
K=1 / 2 \rho A v_{f}{ }^{3} t
$$

The power which is equal to energy per unit time is

$$
\begin{aligned}
& P=d k / d t \\
& P=1 / 2 \rho A v_{f}^{3}
\end{aligned}
$$

Equation 13 gives the available power of the wind but not all the available power can be transferred to the shaft since the air leaves the rotor with a velocity called wake velocity. It was found that, an ideal wind generator with ideal degree of conversion and unlimited capacity may extract at most $60 \%$ of the theoretical energy [9]. Thus the ideal rotor can extract a power

$$
P=C p 1 / 2 \rho A v_{f}^{3}
$$

Where $\mathrm{C}_{\mathrm{p}}$ is the power coefficient equals 0.593 (the Betz limit)

\section{Data And Methods}

There is no standard meteorological station in the Gari River project which takes measurement of wind speed at the standard height of $10 \mathrm{~m}$. The station at Jarda Zone III Bichi, 10 kilometers from the bank of the river and that of Tomas Danbatta, records wind speed at a height of $2.5 \mathrm{~m}$. The Anemometers of these two stations are not functioning for a long time. Therefore the nearest standard station where data could be obtained is Kano $66 \mathrm{Km}$ from Jekarade. The data for the site is evaluated from Kano monthly mean data (2001-2011) using the appropriate wind speed coefficients (Equation 9). Furthermore, Kano and Bagawai fall in the same wind regime. Also, during the hydrological and climatologically survey of the river valley (1981) the wind speed of the site was averaged over Kano and Katsina data.[10]. The twelve-month of the year is divided into rainy and dry seasons, (June-September) and (October-June)

\section{Results And Discussions}

The shape and scale parameters of the Weibull distribution were estimated using spreadsheet software Microsoft Excel and equations 6-9 Table 1. Using the values of $\mathrm{c}$ and $\mathrm{k}$, the Weibull distribution is evaluated and presented in table 2 for both the seasons. The available power density $\left(\mathrm{Wm}^{-2}\right)$ and energy density $\left(\mathrm{Kw}-\mathrm{hm}^{-2}\right)$ for each month of the year at standard meteorological height and $25 \mathrm{~m}$ heights were evaluated using monthly 
mean wind speeds and equations 11-14 and presented in Tables 3 and 4 respectively. Usually wind turbines are installed at $25 \mathrm{~m} \mathrm{[11]}$

Table 1: The Weibull Parameters

\begin{tabular}{|c|c|c|}
\hline & $\mathrm{K}$ & $\mathrm{C}(\mathrm{m} / \mathrm{s})$ \\
\hline Wet Season & 3.3 & 3.46 \\
\hline Dry Season & 3.18 & 3.21 \\
\hline
\end{tabular}

Figure 1 shows the variation of wind speed of the site throughout the year. The values of the Weibull distribution of the wind speed (table 2) were plotted as shown in figure 2 for both the rainy and dry seasons. Figure 3 compares the mean wind speed, and extractable energy densities at $10 \mathrm{~m}$ and $25 \mathrm{~m}$.

Table 2: Weibull Distribution for both Wet and Dry Seasons

\begin{tabular}{|c|c|c|}
\hline Wind Speed $\mathbf{V}(\mathbf{m} / \mathbf{s})$ & Wet Season $\mathbf{f}_{\mathbf{w}}(\mathbf{v})$ & Dry Season $\mathbf{f}_{\mathbf{w}}(\mathbf{v})$ \\
\hline 1 & 0.053993 & 0.07605 \\
\hline 2 & 0.229495 & 0.282827 \\
\hline 3 & 0.367887 & 0.38163 \\
\hline 4 & 0.265119 & 0.213774 \\
\hline 5 & 0.076481 & 0.043445 \\
\hline 6 & 0.00721 & 0.002594 \\
\hline 7 & 0.000174 & $3.56 E-05$ \\
\hline 8 & $8.20 E-07$ & $8.65 E-08$ \\
\hline
\end{tabular}

Table 3:Arrangement of mean wind speed, power density and energy density of Bagwai at 10m

\begin{tabular}{|c|c|c|c|c|c|}
\hline \multirow[b]{2}{*}{ Months } & \multirow[b]{2}{*}{ MEAN V(m/s) } & \multicolumn{2}{|c|}{ Power Density (w/m2) } & \multicolumn{2}{|c|}{$\begin{array}{c}\text { Energy Density } \\
(\mathrm{Kwh} / \mathrm{m} 2)\end{array}$} \\
\hline & & Available & Extractable & Available & $\begin{array}{l}\text { Extracta } \\
\text { ble }\end{array}$ \\
\hline January & 3.35 & 22.93 & 13.60 & 17.06 & 10.12 \\
\hline February & 3.54 & 27.06 & 16.05 & 18.18 & 10.78 \\
\hline March & 3.41 & 24.19 & 14.34 & 18.00 & 10.67 \\
\hline April & 3.35 & 22.93 & 13.60 & 16.51 & 9.79 \\
\hline May & 3.61 & 28.70 & 17.02 & 21.35 & 12.66 \\
\hline June & 3.88 & 35.63 & 21.13 & 25.65 & 15.21 \\
\hline July & 3.24 & 20.75 & 12.30 & 15.44 & 9.15 \\
\hline August & 2.97 & 15.98 & 9.48 & 11.89 & 7.05 \\
\hline September & 2.87 & 14.42 & 8.55 & 10.38 & 6.16 \\
\hline October & 2.55 & 10.11 & 6.00 & 7.53 & 4.46 \\
\hline November & 2.66 & 11.48 & 6.81 & 8.27 & 4.90 \\
\hline December & 3.14 & 18.89 & 11.20 & 14.05 & 8.33 \\
\hline Average & 3.2142 & 21.0894 & 12.5060 & 15.3592 & 9.1080 \\
\hline
\end{tabular}

Table 4: Arrangement of mean wind speed, power density and energy density of Jekarade at $25 \mathrm{~m}$

\begin{tabular}{|l|c|c|c|c|c|}
\hline \multirow{2}{*}{ Months } & \multirow{2}{*}{ MEAN V(m/s) } & \multicolumn{2}{c|}{ Power Density (w/m2) } & \multicolumn{2}{c|}{ Energy Density (Kwh/m2) } \\
\cline { 3 - 6 } January & Available & Extractable & Available & Extractable \\
\hline February & 4.82 & 34.00 & 20.16 & 25.30 & 15.00 \\
\hline March & 3.89 & 40.22 & 23.85 & 27.03 & 16.03 \\
\hline April & 3.82 & 35.91 & 21.29 & 26.71 & 15.84 \\
\hline May & 4.11 & 42.00 & 20.16 & 24.48 & 14.52 \\
\hline June & 4.42 & 52.67 & 31.24 & 37.93 & 22.49 \\
\hline July & 3.69 & 30.65 & 18.17 & 22.80 & 13.52 \\
\hline August & 3.39 & 23.76 & 14.09 & 17.68 & 10.48 \\
\hline September & 3.27 & 21.33 & 12.65 & 15.36 & 9.11 \\
\hline October & 2.91 & 15.03 & 8.91 & 11.18 & 6.63 \\
\hline November & 3.03 & 16.97 & 10.06 & 12.22 & 7.25 \\
\hline
\end{tabular}




\begin{tabular}{|l|c|c|c|c|c|}
\hline December & 3.58 & 27.99 & 16.60 & 20.82 & 12.35 \\
\hline Average & 3.6637 & 31.2410 & 18.5259 & 22.7520 & 13.4919 \\
\hline
\end{tabular}

. The density of air is estimated at $1.185 \mathrm{Kg} / \mathrm{m}^{3}$

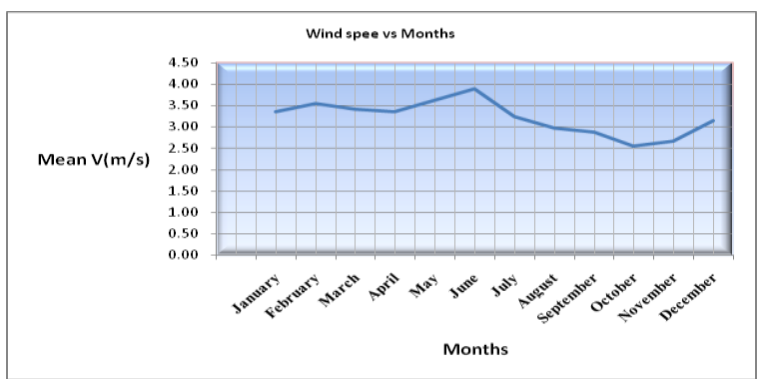

Figure 1 Variation of the mean monthly wind speed at $10 \mathrm{~m}$

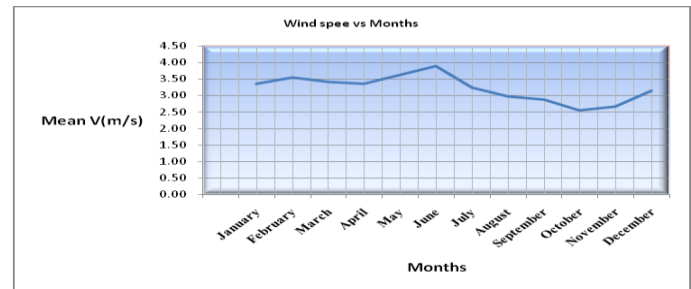

Figure 1 Variation of the mean monthly wind speed at $25 \mathrm{~m}$

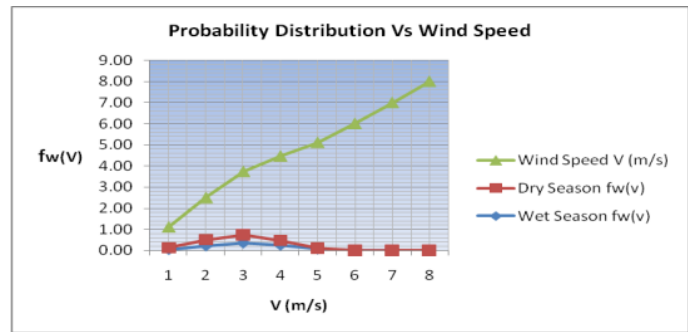

Figure 2; Weibull probability distribution of wind speed for both rainy and dry seasons

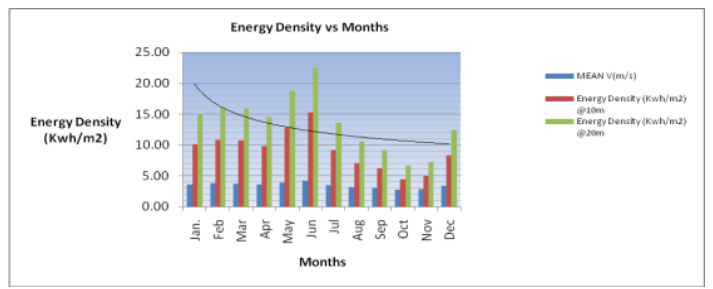

Figure 3: The Mean wind speed, and Extractable Energy Densities at 10m and 25m.

From the graphs the Weibull distribution shows that, the speed with the highest frequency is $3 \mathrm{~m} / \mathrm{s}-$ over $35 \%$ - for both seasons. The analysis shows that, the maximum average wind speed occurs in the month of June is $3.88 \mathrm{~m} / \mathrm{s}$, while the corresponding minimum average occurs in the month of October with average wind speed of $2.55 \mathrm{~m} / \mathrm{s}$.

The maximum power and energy densities were experienced in the month of June while the minimum occur in October. It can be observed that the wind energy is high in the beginning of the wet season, may, and decline towards September. However, rainfall is rising to its peak within that range.

\section{Conclusion}

By using metrological data collected from the weather stations analysis of such data shows that wind power prospects in site is high. From the analysis also, it was clearly seen that At least $60 \%$ of the time in a year has wind speed above the cut-in wind speed of $2.2 \mathrm{~m} / \mathrm{s}$ will be cost effective for water pumping 


\section{Reference}

[1] Som A, K. (1991),An assessment of wind energy potential of Bahrain, Proceeding of ISES, Solar congress, Colarado U.S.A. Vol. 2 pp587-598

[2] U.S.A. Department of energy Energy Efficiency and Renewable Energy., http://www.eere.energy.gov/wind and hydro/wind-rd.html.

[3] Aidan J and Ododo (2010), Wind energy distribution and power Densities of some cities in northern Nigeria, Journal of Engineering and Applied Sciences, Vol. 5 Issue 6, pg 420-424.

[4] Eggleston, D.M.,and F. S. Stoddard, (1987), Wind Turbine Engineering Design, Van Nostrand Reinhold, New York.

[5] National Research Council Energy Engineering, Burd,Assessment Of Research Needs For Wind Turbine Rotor Materials Technology

[6] Ojosu J.O. and Salawu R.I (1990), An evaluation of wind energy potential as power generation source in Nigeria Solar and wind Technology Vol. 7 No6, pp663-673

[7] Celik A. N. (2003) A statistical analysis of wind power density based on the Weibull and Rayleigh models at the southern region of Turkey. Renewable energy 29 pp593-604. www.elsevier.com

[8] Ministry of Agriculture and Natural Resources, Kano State, Nigeria, (1981), Gari irrigation scheme. Annex C. Climate \& Hydrology.

[9] Adaramola M. S. And Oyewola O. M. (2011), Wind speed distribution and characteristics in Nigeria, ARPNJournal of Engineering and Applied Sciences, Vol. 6, No. 2,pg 82-86.

[10] Estimation of the weibull parameters Reliasoft Corporation, 11/15/2011 http://www.weibull.com/LifeDataWeb/estimation_of the weibull_parameter.htm

[11] Fadare D. A. (2008), A statistical analysis of wind energy potential in Ibadan, Nigeria, based on Weibull distribution function, The Pacific Journal of Science and Technology, Vol. 9, No. 1.

[12] Wind Energy Reference Manual, 19997-2003 Danish Wind Industry Association. 